www.jmscr.igmpublication.org

Impact Factor 5.84

Index Copernicus Value: 71.58

ISSN (e)-2347-176x ISSN (p) 2455-0450

crossref DOI: _https://dx.doi.org/10.18535/jmscr/v5i12.156

Journal Of Medical Science And Clinical Research

IGM Publication

An Official Publication of IGM Publication

\title{
Prediction of Early Ventilator Associated Pneumonia using Clinical Pulmonary Infection Score and C-Reactive Protein- A Prospective Observational Study
}

\author{
Authors \\ Dr Basanth Kumar $\mathbf{S}^{1}$, Dr Mohammad Fakruddin², Dr Neelkanth $\mathbf{M G}^{3}$, \\ Dr Padmini $\mathrm{SN}^{4}$ \\ ${ }^{1}$ Associate Professor, Dept of General Medicine KIMS Hospital Bengaluru, India \\ ${ }^{2,3,4}$ Junior Resident Dept of General Medicine KIMS Hospital Bengaluru, India
}

\begin{abstract}
Background \& Objectives: Ventilator associated pneumonia (VAP) is an important form of hospital acquired pneumonia (HAP), specifically developing in a mechanically ventilated patient more than 48 hours after tracheal intubation. The overall or crude mortality associated with VAP ranges from $40 \%$ to $70 \%$ varying with underlying illness. Recent studies have shown that Clinical pulmonary infection score and CRP are valuable tool in detection of early VAP. The aim of the study was correlate clinical pulmonary infection score and creactive protein in the prediction of early ventilator associated pneumonia

Methods: In this study we have taken 30 patients who were above 18 yrs diagnosed to have Early Ventilator associated pneumonia and subjects on immunosuppressive therapy, chemotherapy and AIDS, Patient intubated outside hospital and refered were excluded. Serial CRP levels were measured later CPIS was calculated With the onset of chest infilterate, ET Tube Aspirate culture was obtained for confirmation of VAP.

Results: 30 patients were enrolled. CPIS Score was calculated in 22 patients who developed early VAP which is confirmed by ET tube aspirate culture and sensitivity. CPIS Score of > 6 in cases who developed early VAP which is confirmed by ET Culture and sensitivity was statistically significant on Day 4 with p value of 0.016, But it was not significant on Day 3 and 5 .Over all statistical analysis of CPIS Value of >6 in 18 patients who developed early VAP was significant (P value 0.003). There was serial rise in the titers of CRP levels but CRP levels did not show any stastical significance with CPIS score in VAP patients.

Conclusion: Study showed when the CPIS exceeded 6, there was an association with the presence of pneumonia in mechanically ventilated patients which was confirmed by ET tube aspiration culture. serum CRP is an easy, available and cheap test so serial rise in titres of CRP in mechanically ventilated patients along with CPIS helps in the early diagnosis of pneumonia and aggressive treatment to prevent mortality and morbidity.
\end{abstract}

Keywords: Ventilator associated pneumonia; C reactive protein; Clinical pulmonary infection score; Hospital acquired pneumonia.

\section{Introduction}

Ventilator associated pneumonia (VAP) is an important form of hospital acquired pneumonia (HAP), specifically developing in a mechanically ventilated patient more than 48 hours after tracheal intubation ${ }^{1}$.

VAP results from aspiration of stomach contents and aspiration or migration of bacteria contain- 
ing secretions down the endotracheal tube (ETT) from the oropharynx into the lungs $\mathrm{s}^{2,3,4,13}$.

The overall or crude mortality associated with VAP ranges from $40 \%$ to $70 \%$ varying with underlying illness ${ }^{10}$.

Most clinicians continue to rely on a clinical diagnosis of HAP because it is convenient.

The presence of pneumonia is defined by new lung infiltrate plus clinical evidence that the infiltrate is of an infectious origin. The presence of a new or progressive radiographic infiltrate plus at least two of three clinical features

1) fever greater than 38 degree $C$

2) leucocytosis or leucopenia, and

3) purulent secretions

These represents the most accurate combination of criteria for starting empiric antibiotic therapy ${ }^{10}$.

Requiring all three clinical criteria is too insensitive and it will result in many patients with true pneumonia not receiving therapy.

Ventilator-associated pneumonia is usually suspected when the individual develops a new or progressive infiltrate on chest radiograph, leukocytosis, and purulent tracheobronchial secretions. Unfortunately, and unlike for community-acquired pneumonia, accepted clinical criteria for pneumonia are of limited diagnostic value in definitively establishing the presence of $\mathrm{VAP}^{4}$.

It is the second most common nosocomial infection in the intensive care unit (ICU) and the most common in mechanically ventilated patients $^{5,6,7}$. VAP rates range from 1.2 to 8.5 per 1,000 ventilator days and are reliant on the definition used for diagnosis . Risk for VAP is greatest during the first 5 days of mechanical ventilation $(3 \%)$ with the mean duration between intubation and development of VAP being 3.3 days This risk declines to $2 \%$ /day between days 5 to 10 of ventilation, and $1 \%$ /day thereafter ${ }^{5,8}$.

Early onset VAP is defined as pneumonia that occurs within 5 days and this is usually attributed to antibiotic sensitive pathogens whereas late onset VAP is more likely caused by multidrug resistant (MDR) bacteria and emerges after 5 days of intubation $^{6,8}$.
In an effort to improve the specificity of clinical diagnosis, Pugin et al. developed the clinical pulmonary infection score (CPIS) ${ }^{10,11}$. It has been observed that when CPIS exceeded 6, good correlation with the presence of pneumonia in ventilated patients, which is evident by quantitative cultures of bronchoscopic and non bronchoscopic BAL (Broncho alveolar lavage) specimens ${ }^{10,13}$

\section{Materials and methods}

This was prospective observational study conducted in Kempegowda Institute of Medical Sciences \& Research centre, Bengaluru which is a tertiary care teaching hospital. The study was carried out for a period of 24 months (from January 2015 to December 2016). It is a prospective observational study. The Ethical Committee clearance was obtained and informed consent was taken from the participating patients.

All adults both males and females with age more than 18 years admitted mechanically ventilated in ICU KIMS Hospital Bangalore without chest infilterate for 48hours after mechanical ventilation were included in study. Patient intubated outside, who are on immunosuppressive therapy, chemotherapy, who is diagnosed to have HIV infection and elevated total count at admission were excluded from the study.

Detailed history including age, sex and history of other diseases were obtained, Thorough clinical examination including general examination and local chest examination was conducted, Daily Laboratory investigations, Radiological evaluation for new pulmonary infiltrates was carried out by Plain X-rays. Serum C-reactive protein (CRP) assessment was done $1^{\text {st }} 3^{\text {rd }}, 4^{\text {th }}$ and $5^{\text {th }}$ day during the first 5 days of intubation. Clinical pulmonary infection score (CPIS) at the onset of chest infilterate was calculated. ET Tube culture/ET Tube aspirate culture was done at the onset of chest infilterate. Patient were followed up, outcome noted as discharged, died and discharged against medical advice. 


\section{Figure 1: Clinical pulmonary infection}

\begin{tabular}{|c|c|c|}
\hline Component & Value & Point \\
\hline \multicolumn{3}{|l|}{ Temperature ${ }^{0} \mathrm{C}$} \\
\hline & $\geq 36.5$ and $\leq 38.4$ & 0 \\
\hline & $\geq 38.5$ and $\leq 38.9$ & 1 \\
\hline & $\geq 39.0$ and $\leq 36.0$ & 2 \\
\hline \multirow[t]{2}{*}{ Blood leukocytes (mm3) } & $\geq 4000$ and $\leq 11000$ & 0 \\
\hline & $<4000$ or $>11000$ & 1 \\
\hline \multirow[t]{4}{*}{ Tracheal secretions } & Few & 0 \\
\hline & Moderate & 1 \\
\hline & Large and purulent & 2 \\
\hline & (>25 PNL per LPF) & \\
\hline \multicolumn{3}{|l|}{ Oxygenation } \\
\hline \multirow[t]{2}{*}{ (Pa02/Fi02, mm Hg) } & $>240$ or presence of ARDS & 0 \\
\hline & $\leq 240$ and absence of ARDS & 2 \\
\hline \multirow[t]{3}{*}{ Chest radiograph } & No infiltrate & 0 \\
\hline & Patchy or diffuse infiltrate & 1 \\
\hline & Localized infiltrate & 2 \\
\hline \multicolumn{3}{|l|}{ Progression of pulmonary } \\
\hline \multirow[t]{3}{*}{ Infiltrate } & No radiographic progression & 0 \\
\hline & Radiographic progression & 2 \\
\hline & (After CHF and ARDS excluded & \\
\hline \multirow[t]{4}{*}{ Culture } & $<10000$ cfu bacteria & \\
\hline & per ml BAL or no growth & 0 \\
\hline & $\geq 10000$ cfu bacteria & \\
\hline & per ml BAL & 1 \\
\hline
\end{tabular}

ARDS, Acute Respiratory Distress Syndrome; BAL, Bronchoalveolar Lavage; CFU, Colony Forming Unit; CHF, Congestive Heart Failure; CPIS. Clinical Pulmonary Infection Score; $\mathrm{FiO}_{2}$, Fraction of inspired oxygen; LPF, Low Power Field; $\mathrm{PaO}_{2}$, Partial arterial oxygen; PNL, Polymorphonuclear Neutrophils.

\section{Statistical Analysis}

The resultsfor each parameter (numbers and percentage) for discrete data and averaged (mean+/-standard deviation) for continuous data are presented in Table and figures. Student $t$ test, one way Analysis of Variance (Anova) and pearson correlation were used . $\mathrm{p}$ value less than 0.05 was considered as statistically significant. Data analysis was carried out using statistical package for social science (SPSS V 10.5)

\section{Results}

In this study 30 patients who were admitted to KIMS hospital ICU and mechanically ventilated who developed Ventilator associated Pneumonia were enrolled. All patients were above 18 years and most of them were in the age group of 41-50 age group (30\%) and out of 30 patients 25 were male and 05 were female patients, Male to Female ratio is $5: 1$.
Table 1: Distribution of cases according to Diagnosis

\begin{tabular}{|l|c|c|}
\hline DIAGNOSIS & N & \% \\
\hline OP COMPOUND & 10 & 33.3 \\
\hline UNKNOWN POISON & 5 & 16.7 \\
\hline RTA HEAD INJUY & 4 & 13.3 \\
\hline CVA-ISCHEMIC STROKE & 4 & 13.3 \\
\hline CVA-HEM STROKE & 2 & 6.7 \\
\hline GB SYNDROME & 1 & 3.3 \\
\hline HEAD INJURY -SELF FALL & 2 & 6.7 \\
\hline METABOLIC ENCEPHALOPATHY & 1 & 3.3 \\
\hline ALCOHOL INTOXICATION & 1 & 3.3 \\
\hline TOTAL & 30 & 100.0 \\
\hline
\end{tabular}

$33.3 \%$ cases had Organo phosphorus compound poisoning, $16.7 \%$ cases had unknown compound poisoning, $13.3 \%$ cases had head injury, $13.3 \%$ cases had ischemic stroke, $6.7 \%$ cases had hemmorrhegic stroke. These were major number of cases in study

Table 2: Distribution of cases according to CoMorbidities

\begin{tabular}{|l|c|c|}
\hline CO-MORBIDITIES & N & \% \\
\hline TYPE2 DM & 8 & 26.7 \\
\hline HYPERTENSION & 7 & 23.3 \\
\hline THYROID DISORDER & 4 & 13.3 \\
\hline CORONARY ARTERY DISEASE & 5 & 16.7 \\
\hline COPD & 2 & 6.7 \\
\hline OLD TB & 2 & 6.7 \\
\hline SEIZZURE DISORDER & 1 & 3.3 \\
\hline OLD CVA & 3 & 10 \\
\hline BRONCHIAL ASTHMA & 3 & 10 \\
\hline
\end{tabular}

In our study $26.7 \%$ had Type 2 Diabetes, $23.3 \%$ of them had HTN followed by IHD $16.7 \%$ as the commonest co-morbidity. 
Figure 2: Distribution CXR findings among the study population $(\mathrm{N}=30)$

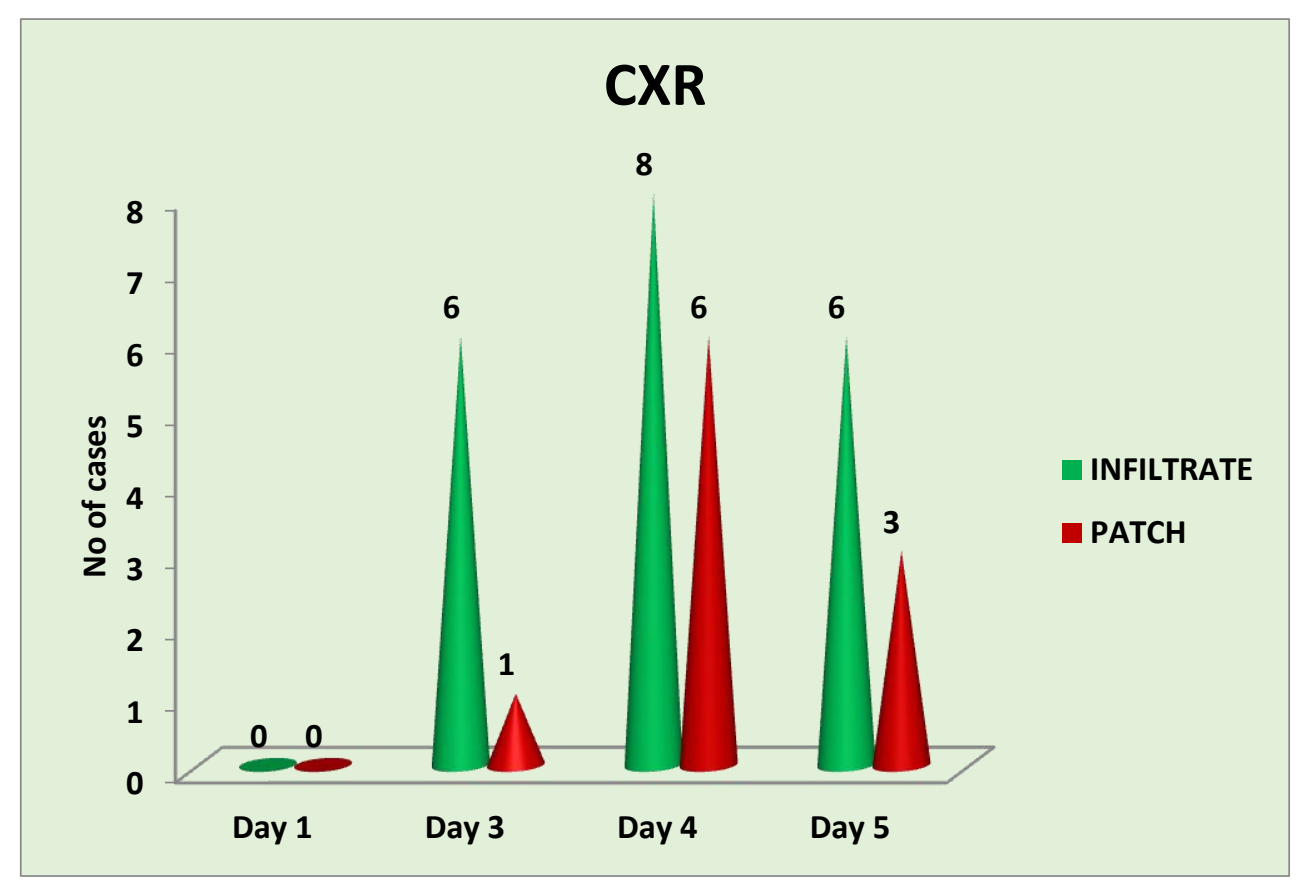

On Day 1 all cases had normal chest X Ray, On Day 3 chest X Ray showed infilterate in 6(20\%) cases and patch $(3.3 \%)$ in 1 case, On Day 4 inflitrates were present in $8(26.7 \%)$ cases and patch was present in $6(20 \%)$ cases, On Day 5 infilterates were present in $6(20 \%)$ cases and patch in $3(10 \%)$ cases.

Figure 3: Mean CRP by days among study population

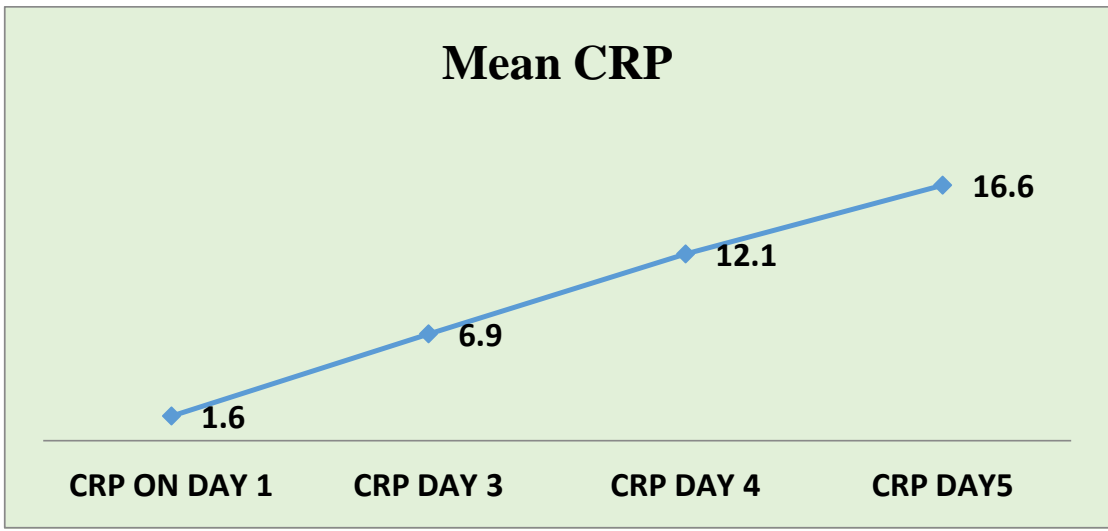

Mean CRP was $1.6 \pm 1.3$ on Day $1,6.9 \pm 3.2$ on Day $3,12.1 \pm 4.8$ on Day 4 and was $16.6 \pm 6.9$ on Day 5 .

Table 3: ET Culture Growth and CPIS among study population

\begin{tabular}{|l|c|c|c|c|c|}
\hline \multirow{2}{*}{ CPIS } & \multicolumn{2}{|c|}{$\leq \mathbf{6}$} & \multicolumn{2}{c|}{$>\mathbf{6}$} & \multirow{2}{*}{ p value } \\
\cline { 1 - 5 } ET CULTURE GROWTH & $\mathbf{N}$ & $\%$ & $\mathbf{N}$ & $\%$ & \\
\hline Day 3 & 1 & 25 & 3 & 75 & 0.486 \\
\hline Day 4 & $\mathbf{1}$ & $\mathbf{1 0}$ & $\mathbf{9}$ & $\mathbf{9 0}$ & $\mathbf{0 . 0 1 6}$ \\
\hline Day 5 & 2 & 25 & 6 & 75 & 1.000 \\
\hline
\end{tabular}

Note: *means significant difference at $5 \%$ level of significance

ET culture growth was found in 22(73.33\%) of 30 patients who developed chest X ray infiltrate and patch. 
Table 4: ET Culture Growth and CPIS among study population

\begin{tabular}{|l|c|c|c|c|c|}
\hline CPIS & \multicolumn{2}{|c|}{$\leq 6$} & \multicolumn{2}{|c|}{$>\mathbf{6}$} & \multirow{2}{*}{ p value } \\
\hline \multirow{2}{*}{ ET CULTURE GROWTH TOTAL } & $\mathbf{N}$ & $\%$ & $\mathbf{N}$ & $\%$ & \multirow{2}{*}{$0.003 *$ (SIG) } \\
\cline { 2 - 6 } & 4 & 40 & 18 & 90 & \\
\hline
\end{tabular}

Note: *means significant difference at $5 \%$ level of significance CPIS Score was calculated in 22 patients who developed early VAP which is confirmed by ET tube aspirate culture and sensitivity, CPIS Score was $\leq 6$ in 1 case on Day 3, 1 case on Day 4 and in 2 cases on Day 5, CPIS Score was $>6$ in 3 cases on Day 3, 9 cases on Day 4 and 6 cases on Day 5, CPIS Score of $>6$ in cases who developed early
VAP which is confirmed by ET Culture and sensitivity was statistically significant on Day 4 with $\mathrm{p}$ value of 0.016 , But it was not significant on Day 3 and 5.

Over all statistical analysis of CPIS Value of $>6$ in 18 patients who developed early VAP was significant ( $\mathrm{P}$ value 0.003 ).

Table 5: Mean CRP level by CPIS categories among study population

\begin{tabular}{|l|c|c|c|c|c|}
\hline CPIS & \multicolumn{2}{|c|}{$\leq \mathbf{6}$} & \multicolumn{2}{c|}{$>\mathbf{6}$} & \multirow{2}{*}{ p value } \\
\hline CRP & Mean & SD & Mean & SD & \\
\hline Day 3 & 6.8 & 2.0 & 7.9 & 1.8 & 0.491 \\
\hline Day 4 & 14.0 & 6.5 & 11.5 & 4.1 & 0.369 \\
\hline Day 5 & 12.4 & 2.6 & 18.0 & 7.5 & 0.362 \\
\hline
\end{tabular}

Mean CRP and Clinical pulmonary infection score levels were not statistical significance, but there was serial rise in titre of CRP value from day 1 to day 5 .

Table 6: ET Aspirate culture of the studied patients

\begin{tabular}{|l|c|c|}
\hline Organism Isolated & No of patients $(\mathbf{n = 2 2})$ & \% \\
\hline Klebsiella pneumonia & 12 & 54.5 \\
\hline Pseudomonas aeruginosa & 10 & 45.5 \\
\hline Streptococcus pneumoniae & 4 & 18.2 \\
\hline MRSA & 8 & 36.4 \\
\hline Acinatobacter & 6 & 27.3 \\
\hline
\end{tabular}

ET Culture growth showed Klebsiella pneumonia in $12(54.5 \%$ ) cases, Pseudomonas aeruginosa in $10(45.5 \%)$ cases, MRSA in $8(36.4 \%)$ cases, Acinatobacter in $6(27.3 \%)$ cases and streptococcus pneumonia in $4(18.2 \%)$ cases. Multiple organisms have been isolated from same cases. Most of the organisms were multi drug resistant.
Table 7: Outcome among study population

\begin{tabular}{|l|c|c|}
\hline OUTCOME & $\mathbf{N}$ & $\mathbf{\%}$ \\
\hline DEATH & 12 & 40 \\
\hline DISCHARGE & 17 & 56.7 \\
\hline DAMA & 1 & 3.3 \\
\hline TOTAL & 30 & 100 \\
\hline
\end{tabular}

Of 30 cases $17(40 \%)$ were discharged after treating, $12(56.7 \%)$ cases died and $1(3.3 \%)$ diacharged against medical advice.

Figure 4: Comparison of CXR and CPIS among study population (N=30)

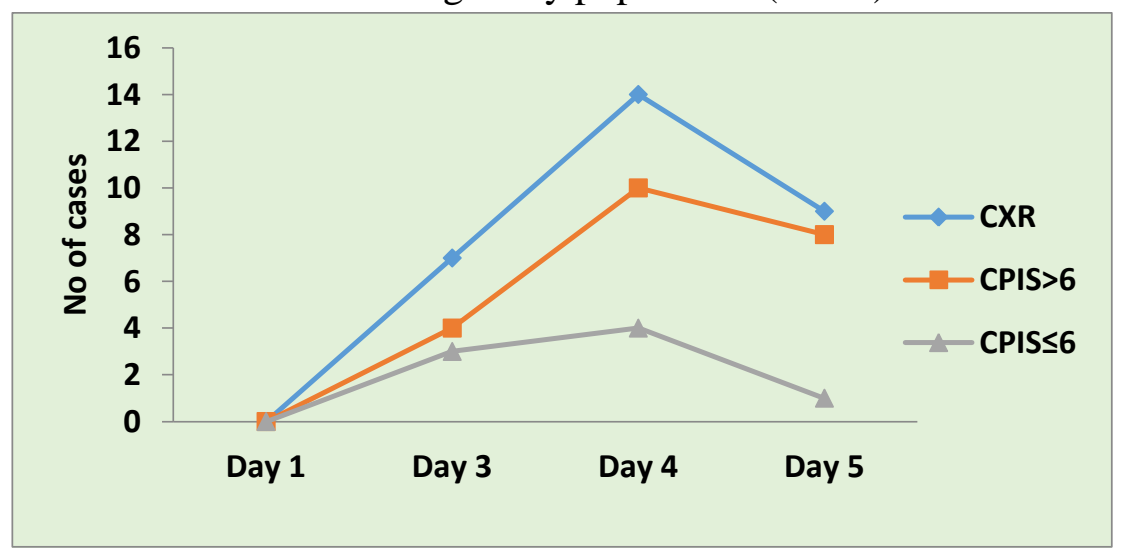


Table 8: Descriptive statistics of Subjects

\begin{tabular}{|l|c|c|c|}
\hline Variables & Range & Mean & SD \\
\hline AGE ( IN YEARS) & $24-79$ & 45.9 & 15.8 \\
\hline HR/MIN @ ADMISSION & $56-120$ & 94.1 & 18.1 \\
\hline RR cpm & $12-38$ & 21.2 & 7.9 \\
\hline SPo2 AT RA & $64-97$ & 88.3 & 7.4 \\
\hline GCS @ ADMISSION & $3-13$ & 7.7 & 2.3 \\
\hline HB gm/dl & $7.8-17.4$ & 12.9 & 2.1 \\
\hline WBC COUNT & $4170-16440$ & 8687.3 & 3102.8 \\
\hline PLATELET COUNT (LACKS) & $0.73-3.99$ & 2.2 & 0.9 \\
\hline B.UREA & $12-103$ & 33.9 & 18.7 \\
\hline S.CREATINE mg/dl & $0.5-4.3$ & 1.0 & 0.7 \\
\hline LENGTH OF ICU STAY & $6-40$ & 16.2 & 9.7 \\
\hline
\end{tabular}

\section{Discussion}

Ventilator associated pneumonia is important form of hospital acquired pneumonia, The single greatest risk factor for VAP is related to the duration of mechanical ventilation. Early VAP occurs within the first 5 days of intubation. Lateonset VAP occurs after 5 days, is more commonly caused by multidrug resistant (MDR) pathogens, and carries higher morbidity and mortality ${ }^{10}$. In our study, out of 30 cases who developed VAP on chest X ray, $22(73.33 \%)$ cases had ET culture aspirate growth. CPIS Score was calculated in 22 patients who developed early VAP which is confirmed by ET tube culture and sensitivity CPIS Score was $\leq 6$ in 4 patients, CPIS Score was $>6$ in 18 patients. CPIS Score of $>6$ in cases who developed early VAP which is confirmed by ET Culture and sensitivity was statistically significant on Day 4 with $\mathrm{p}$ value of 0.016 , But it was not significant on Day 3 and 5 .Over all statistical analysis of CPIS Value of $>6$ in 18 patients who developed early VAP was significant $(P$ value 0.003 ). Out of 30 cases 12 patients succumbed to death. Most common factors associated with mortality includes VAP due to Multi drug resistant organism, underlying other co morbid conditions.

Ventilator-associated pneumonia is an important cause of morbidity and mortality in critically ill patients. Evidence-based clinical practice guidelines for the prevention, diagnosis, and treatment of ventilator-associated pneumonia may improve outcomes.
Enas Elsayed Mohamed et al in 2013 reported, serum CRP increased in 32 patients. CPIS of the studied patients at the onset of rising serum CRP ranged from 7 to 10 in 24 patients. In the first 5 days of intubation, 32 patients out of 80 patients had high CRP, those were $40 \%$ of the study population and 24 patients of those 32 patients had high CPIS; those were $30 \%$ of the study population and $75 \%$ of patients had high $\mathrm{CRP}^{10}$.

Pham et al reached a similar conclusion in their assessment of CPIS in the treatment of burn patients. These investigators retrospectively calculated the CPIS for 28 patients who had 46 quantitative cultures performed to diagnose VAP and tested the characteristics of a CPIS threshold of 6 for the diagnosis of VAP. They found that the CPIS had poor discrimination; patients with positive and negative culture results had a similar CPIS (the mean CPIS was 5.7 and 5.5, respectively), and the sensitivity and specificity of the CPIS was $30 \%$ and $80 \%$, respectively ${ }^{14}$.

Smith et al used CRP as a useful sensitive marker of bacterial infection in cases of pneumonia. There was marked elevation of serum level of CRP within a few hours of Infection ${ }^{15}$.

In this study CRP levels did not show any stastical significance with CPIS score in VAP patients, the reason mostly because CRP will be elevated in many condition like acute stress and associated infections like urinary tract infection, catheter related infections etc, but serial rise in CRP levels with CPIS score will be useful in detection of early VAP. 


\section{Conclusion}

Clinical pulmonary infection score is an easy scoring system for the diagnosis of early Ventilator associated pneumonia. When the CPIS exceeded 6, there was an association with the presence of pneumonia in mechanically ventilated patients which was confirmed by ET tube aspiration culture .Serum CRP is an easy, available and cheap test so serial rise in titres of CRP in mechanically ventilated patients along with CPIS helps in the early diagnosis of pneumonia and aggressive treatment to prevent mortality and morbidity.

\section{References}

1. Hina Gadani, Arun Vyas, and Akhya Kumar Kar study of ventilator-associated pneumonia: Incidence, outcome, risk factors and measures to be taken for prevention : Indian J Anaesth. 2010 NovDec; 54(6): 535-540.

2. Koenig S, Truwit JD. Ventilator associated pneumonia: diagnosis, treatment, and prevention. Clin Micr Reviews 2006;19(4):637-657.

3. Fagon J, Chastre J, Hance A, Montravers P, Novara A,and Gibert C. Nosocomial pneumonia in ventilated patients:a cohort studyevaluating attribut able mortality and hospital stay.Am J Med 1993;94:281-288.

4. Rello J, Ollendorf D, Oster G, Vera - Llonch M, Bellm L, Redman RKo llef M.Epidemiology andoutcomes ofv entilator- associated pneumonia ina lar ge US database Chest 2002; 122: 2115- 2121.

5. Atul Ashok Kalanuria, Wendy Zai Email author Ventilator-associated pneumonia in the ICU Critical Care201418:208

6. $\mathrm{H}$ unter JD: Ventilator associated pneumonia. BMJ 2012, 344(e3325):e3325.
7. A fshari A, Pagani L, Harbarth S: Year in review 2011: Critical care - infection. Crit Care 2012, 16:242-247

8. A merican Thoracic Society, Infectious Diseases Society of America: Guidelines for the management of adults with hospital-acquired, ventilator-associated, and healthcare-associated pneumonia. Am J Respir Crit Care Med 2005, 171:388416.

9. Kollef M, Silver P, Murphy D, and Trovillion E. The effect of late- o nsetventilator- associated pneumonia in determining patient mortality. Chest 1995; 108(6): 1665- 1662.

10. Enas Elsayed Mohamed *, Alaa El Din Ali Abd Alla ; Clinical pulmonary infection score and C-reactive protein in the prediction of early ventilator associated pneumonia : Egyptian Journal of Chest Diseases and Tuberculosis (2013) 62, 453 458

11. J. Pugin, R. Auckenthaler, N. Mili, et al, Diagnosis of ventilator- associated pneumonia by bacteriologic analysis of bronchoscopic and non-bronchoscopic "blind" bronchoalveolarlavage fluid, Am. Rev. Respir. Dis. 149 (1991) 1121-1129.

12. Steven M. Koenig and Jonathon D. Truwit ${ }^{*}$ Ventilator-Associated Pneumonia: Diagnosis, Treatment, and Prevention Clin Microbiol Rev. 2006 Oct; 19(4): 637-657.

13. American Thoracic Society, Guidelines for the management of adult with hospital acquired, ventilator - associated, and healthcare - associated pneumonia, Am. J. Respir. Crit. Care Med. 171 (2005) 388416.

14. T.N. Pham, M.J. Neff, J.M. Simmons, et al, The Clinical Pulmonary Infection Score poorly predicts pneumonia in patients with burns, J. Burn Care Res. 28 (2007) 76-79.

15. R.P. Smith, B.J. Lipo worth, C-reactive protein in simple community - acquired pneumonia, Chest 107 (1995) 1028-1031. 
16. M. Fartoukih, B. Maitre, S. Honore, et al, Diagnosing pneumonia during mechanical ventilation: the clinical pulmonary infection score revisited, Am. J. Respir. Crit. Care Med. 168 (2003) 173-179.

17. Chastre J, Fagon JY. Ventilator-associated pneumonia. Am J Respir Crit Care Med 2002;165:867-903.

18. Rello J, Ollendorf DA, Oster G, Montserrat V, Bellm L, Redman R, Kollef MH. Epidemiology and outcomes of ventilator-associated pneumonia in a large US database. Chest 2002;122:2121.

19. Cook DJ, Walter SD, Cook RJ, Griffith LE, Guyatt GH, Leasa D, Jaeschke RZ, Brun-Buisson $\mathrm{C}$. Incidence of and risk factors for ventilator-associated pneumonia in critically ill patients. Ann Intern Med 1998;129:440.

20. Brochard L, Mancebo J, Wysocki M, Lofaso F, Conti G, Rauss A, Simonneau G, Benito S, Gasparetto A, Lemaire F. Noninvasive ventilation for acute exacerbations of chronic obstructive pulmonary disease. N Engl J Med 1995;333:817-822.

21. Antonelli M, Conti G, Rocco M, Bufi M, De Blasi RA, Vivino G, Gasparetto A, Meduri GU. A comparison of noninvasive positivepressure ventilation and conventional mechanical ventilation in patients with acute respiratory failure. $\mathrm{N}$ Engl J Med 1998;339:429-435.

22. Hilbert G, Gruson D, Vargas F, Valentino R, Gbikpi-Benissan G, Dupon M, Reiffers $\mathrm{J}$, Cardinaud JP. Noninvasive ventilation in immunosuppressed patients with pulmonary infiltrates, fever, and acute respiratory failure. $\mathrm{N}$ Engl $\mathrm{J}$ Med 2001;344:817-822.

23. Jean Chastre, Md • Charles-Edouard Luyt, MD, PhD Ventilator-Associated Pneumonia Murray and Nadel's Textbook of Respiratory Medicine (Sixth Edition) 2016, Pages 583-592.e5
24. Nasia Safdar MD MSc, Christopher J Crnich MD MSc, and Dennis G Maki MD The Pathogenesis of Ventilator-Associated Pneumonia: Its Relevance to Developing Effective Strategies for Prevention RESPIRATORY CARE • JUNE 2005 VOL 50 NO 6

25. Lees AW, McNaught W. Bacteriology of lower-respiratory-tract secretions, sputum, and upper-respiratory-tract secretions in "normals" and chronic bronchitics. Lancet 1959;2:1112-1115.

26. Laurenzi GA, Potter RT, Kass EH. Bacteriologic flora of the lower respiratory tract. N Engl J Med 1961;265:1273-1278

27. Salathe M, Wanner A. Nospecific host defenses: mucociliary clearance and cough. In: Niederman M, ed. Respiratory Infections. Philadelphia: Saunders; 1994:17-32.

28. Zeiher BG, Hornick DB. Pathogenesis of respiratory infections and host defenses. Curr Opin Pulm Med 1996;2(3):166-173.

29. Strieter RM, Belperio JA, Keane MP. Host innate defenses in the lung: the role of cytokines. Curr Opin Infect Dis 2003;16(3):193- 198 .

30. Klainer AS, Turndorf $\mathrm{H}, \mathrm{Wu} \mathrm{WH}$, Maewal $\mathrm{H}$, Allender P. Surface alterations due to endotracheal intubation. Am $\mathrm{J}$ Med 1975;58(5): 674-683.

31. Cooper JD, Grillo HC. Experimental production and prevention of injury due to cuffed tracheal tubes. Surg Gynecol Obstet 1969; 129(6):1235-1241.

32. Levine SA, Niederman MS. The impact of tracheal intubation on host defenses and risks for nosocomial pneumonia. Clin Chest Med 1991;12(3):523-543.

33. Bone DK, Davis JL, Zuidema GD, Cameron JL. Aspiration pneumonia. Prevention of aspiration in patients with tracheostomies. Ann Thoracic Surg 1974;18(1):30-37. 
34. Safdar N, Maki DG. The commonality of risk factors for nosocomial colonization and infection with antimicrobial-resistant Staphylococcus aureus, enterococcus, Gram-negative bacilli, Clostridium difficile and Candida. AnnIntern Med2002;136(11): 834-844.

35. de la Torre FJ, Pont T, Ferrer A, Rossello J, Palomar M, Planas M. Pattern of tracheal colonization during mechanical ventilation. Am J Respir Crit Care Med 1995;152(3):1028-1033.

36. Ewig S, Torres A, El-Ebiary M, Fabregas $\mathrm{N}$, Hernandez $\mathrm{C}$, Gonzalez $\mathrm{J}$, et al. Bacterial colonization patterns in mechanically ventilated patients with traumatic and medical head injury. Incidence, risk factors, and association with ventilator-associated pneumonia. Am J Respir Crit Care Med 1999;159(1):188198.

37. George DL, Falk PS, Wunderink RG, Leeper KV Jr, Meduri GU, Steere EL, et al. Epidemiology of ventilator-acquired pneumonia based on protected bronchoscopic sampling. Am J Respir Crit Care Med 1998;158(6):1839-1847.

38. Estes RJ, Meduri GU. The pathogenesis of ventilator-associated pneumonia: I. Mechanisms of bacterial transcolonization and airway inoculation. Intensive Care Med 1995;21(4):365-383.

39. Hamill RJ, Houston ED, Georghiou PR, Wright CE, Koza MA, Cadle RM, et al. An outbreak of Burkholderia (formerly Pseudomonas) cepacia respiratory tract colonization and infection associated with nebulizedalbuterol therapy. AnnIntern Med 1995;122(10): 762-766.

40. Alcon A, Fabregas N, Torres A. Hospitalacquired pneumonia: etiologic considerations. Infect Dis Clin North Am 2003;17 (4):679- 695.
41. Maki DG. Preventing infection in intravenous therapy. Anesth Analg 1977;56(1):141-153.

42. Crnich CJ, Maki DG. The promise of novel technology for the prevention of intravascular device-related bloodstream infection. II. Long-term devices. Clin Infect Dis 2002;34(10):1362-1368.

43. Takigawa K,Fujita J,Negayama K, Yamagishi Y,YamajiY,Ouchi K, et al. Nosocomial outbreak of Pseudomonas cepacia respiratory infection in immunocompromised patients associated with contaminated nebulizer devices. Kansenshogaku Zasshi1993;67(11):11151125.

44. Srinivasan A, Wolfenden LL, Song X, Mackie K, Hartsell TL, Jones HD, et al. An outbreak of Pseudomonas aeruginosa infections associated with flexible bronchoscopes. N Engl J Med 2003; 348(3):221-227.

45. Drinka PJ, Gravenstein S, Krause P, Langer EH, Barthels L, Dissing M, et al. Non-influenza respiratory viruses may overlap and obscure influenza activity. J Am Geriatr Soc 1999;47(9):1087- 1093.

46. Drinka PJ, Gravenstein S, Krause P, Schilling M, Miller BA, Shult P. Outbreaks of influenza A and B in a highly immunized nursing home population. J Fam Pract 1997;45(6):509-514.

47. Drinka PJ, Gravenstein S, Schilling M, Krause P, Miller BA, Shult P. Duration of antiviral prophylaxis during nursing home outbreaks of influenza A: a comparison of 2 protocols. Arch Intern Med 1998;158 (19):2155-2159.

48. Drinka PJ, Krause P, Schilling M, Miller BA, Shult P, Gravenstein S. Report of an outbreak: nursing home architecture and influenza-A attack rates. J Am Geriatr Soc 1996;44(8):910-913.

49. Gravenstein S, Ambrozaitis A, Schilling M, Radzisauskiene D, Krause P, Drinka P, 
et al. Surveillance for respiratory illness in long-term care settings: detection of illness using a prospective research technique. $\mathbf{J}$ Am Med Dir Assoc 2000;1(3):122-128.

50. Schilling M, Gravenstein S, Drinka P, Cox N, Krause P, Povinelli L, Shult P. Emergence and transmission of amantadine-resistant influenza $\mathrm{A}$ in $\mathrm{a}$ nursing home. J Am Geriatr Soc 2004;52(12): 2069-2073.

51. Schilling M, Povinelli L, Krause $P$, Gravenstein M, Ambrozaitis A, Jones HH, et al. Efficacy of zanamivir for chemoprophylaxis of nursing home influenza outbreaks. Vaccine1998;16(18):17711774.

52. Meduri GU, Estes RJ. The pathogenesis of ventilator-associated pneumonia: II. The lower respiratory tract. Intensive Care Med 1995;21(5):452-461.

53. Tablan OC, Anderson LJ, Besser R, Bridges C, Hajjeh R, Healthcare Infection Control Practices Advisory Committee, Centers for Disease Control and Prevention. Guidelines for preventing health-care-associated pneumonia, 2003: recommendations of the $\mathrm{CDC}$ and the Healthcare Infection Control Practices Advisory Committee. MMWR Recomm Rep 2004;53(RR-3):1-36

54. Craven DE, Kunches LM, Kilinsky V, Lichtenberg DA, Make BJ, McCabe WR. Risk factors for pneumonia and fatality in patients receiving continuous mechanical ventilation. Am Rev Respir Dis 1986; 133:792-796. 